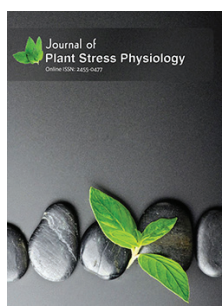

ISSN: $2455^{-0477}$
Received: April 18, 2018 Accepted: June 11, 2018 Published: January 1, 2019

*Corresponding Author: Abderrahim El Keroumi Email: kabderahim@gmail.com

\section{Use of morpho-physiological parameters and biochemical markers to select drought tolerant genotypes of durum wheat}

\author{
Ismaill Outoukarte', Abderrahim El Keroumi'*, Abdelhi Dihazi², \\ Khalid Naamani'
}

'Laboratory of Biotechnologies and Plant Resources Valorization, Cadi Ayyad University, Faculty of Sciences Semlalia, Marrakesh, Morocco, 2laboratory of Biotechnology and Molecular Bio-engineering, Faculty of Sciences and Techniques, Marrakech

\section{ABSTRACT}

Nine durum wheat genotypes (Karim, Ourghi, Massa, Isly, Vitron, Sebou, Oum Rbia, Sarif, and Marzak) were grown in pots and evaluated for their phenolic content and peroxidases activity (POX), cell membrane stability (CMS) and Stomatal Resistance (SR). The genotypes Ourghi and Karim exhibited the highest amount of total phenolics (1374 $\mu \mathrm{g} \cdot \mathrm{g}^{-1} \mathrm{FW}$ and $1303 \mu \mathrm{g} \cdot \mathrm{g}^{-1} \mathrm{FW}$ respectively) while Massa and Oum Rbia showed the lowest amounts $\left(676 \mu \mathrm{g} \cdot \mathrm{g}^{-1} \mathrm{FW}\right.$ and $761 \mu \mathrm{g} \cdot \mathrm{g}^{-1} \mathrm{FW}$ respectively) under severe stress regime. High performances Liquid Chromatography (HPLC) analysis revealed an important accumulation of hydroxycinnamic acid derivatives for the most accumulating genotypes. Under severe drought stress conditions, Ourghi revealed the highest peroxidase activity and Oum Rbia the lowest. A positive correlation was obtained between total phenolics and CMS. In another experiment hold in the hydroponic system under normal growing conditions, we revealed the superiority of genotype Karim in term of tillers, leaves and roots number, root thickness and dry matter accumulation and allocation to the roots. The present data provide useful information about whether the parameters used in this study are helpful in understanding drought tolerance mechanisms and the possibility to use them in selection programs under Mediterranean conditions.

KEYWORDS: Durum wheat; drought stress; peroxidases; phenolics; electrolyte leakage; hydroponics; stomatal resistance.

\section{INTRODUCTION}

Response to drought and concurrent stresses has been the subject of intense research using physiological $[1,2,3]$ and/ or biochemical mechanisms $[4,5,6]$ which are combined to growth attributes for drought tolerance characterization [7] in wheat [8] and turfgrasses [9]. The involvement of antioxidant enzymes and non-enzymatic systems like an accumulation of phenolic compounds against abiotic stresses such as drought has been described in wheat [10]. At the cellular level, stress factors may affect the CMS which is now widely applied to assess the injury caused by several environmental stress factors such as salinity [11, 12], freezing [13] or water deficit [14, 15, 16]. In addition, drought tolerance mechanism may involve some behavioral mechanisms like stomatal closure. This avoidance trait was used to compare plant performance under drought stress conditions [17, 18]. In Grapevine, the stomatal closure was the first response induced under intensified water stress [19].
According to the literature, plants productivity is strongly related to the processes of dry matter accumulation [20] and partitioning [21] under drought conditions. Considering the role of the root system in crop adaptation to drought environment, the root traits have been largely used in selection programs to test the effect of several environmental factors on root growth [22] or for breeding for high yield and growth performance [23]. Because of their ability to improve plant water status under stress conditions the root plasticity and deepens are considered key traits for adaptation to water stress [24, 25]. Generally, it is believed that plants with deeper root systems can tolerate and grow well under stress conditions. Root/shoot ratios were also largely used to compare the effect of several environmental factors on plant growth like drought [26] and low temperature [27].

The experiments undertaken in this study aimed to combine phenolic accumulation and antioxidant enzymatic activity to

\footnotetext{
Copyright: $\odot 2018$ The authors. $\odot$ This article is open access and licensed under the terms of the Creative Commons Attribution License (http:// creativecommons.org/licenses/by/4.0/) which permits unrestricted, use, distribution and reproduction in any medium, or format for any new purpose, even commercially provided the work is properly cited. Attribution - You must give appropriate credit, provide a link to the license, and indicate if changes were made.
} 
growth attributes and membrane stability in order to use as selection criteria for best drought tolerance in durum wheat under arid and semi-arid conditions. The effect of drought stress was revealed on phenolic contents, POX activity and stomatal resistance in pots cultures. This experiment was supported by another experiment hold in hydroponics which consisting in studying the growth kinetics of root and shoot system as well as other growth attributes in order to evaluate the genotypic differences against drought stress.

\section{MATERIAL AND METHODS}

Nine Durum wheat genotypes namely Sarif, Karim, Marzak, Isly, Massa, Ourghi, Sebou, Vitron and Oum Rbia were included in the present study in order to investigate their performance under different growth conditions. Pots experiments were exploited to test phenolic contents, POX activity, cells injuries and stomatal resistance in relation to drought stress. In hydroponics, root, and shoot growth kinetics, biomass production root thickness, root number per plant, leaves and tillers number were analysed.

\section{Phenolic Content And Peroxidase Activity}

Plants of the nine genotypes were grown in pots and were divided into three treatments corresponding to three regimes which consist of irrigation every 30 (moderate stress) 45 days (severe stress) and a control which received the same amount of natural precipitation during the period of the experiment.

For peroxidases analysis, leaf tissue $(200 \mathrm{mg})$ was homogenized in $2 \mathrm{ml}$ of Tris-maleate buffer $\left(\mathrm{pH} 6.5,4^{\circ} \mathrm{C}\right)$ and centrifuged at $7000 \mathrm{~g}$ for $3 \mathrm{~min}$. The pellet obtained was homogenized and centrifuged twice using $500 \mu \mathrm{l}$ of the extraction buffer to exhaust its protein content. The three supernatants were collected and used as enzyme extract. The POX activity was assessed at $470 \mathrm{~nm}$ using guaiacol as the hydrogen donor. The reaction mixture was composed by $10 \mu \mathrm{l}$ of protein extract and $2 \mathrm{ml}$ of Tris-maleate-Gaïacol-CaCl2. The reaction was catalyzed by adding $20 \mu \mathrm{l}$ of $\mathrm{H}_{2} \mathrm{O}_{2}$ at $10 \%$, the increase of absorbance was followed continuously for $3 \mathrm{~min}$ and peroxidase activity was expressed on a fresh weight basis (units per gram fresh weight). One unit was defined as the amount of enzyme that gave a change in absorbance of 0.1 in 1 min [28]

Total soluble phenolics were extracted from leaves by grounding $0.2 \mathrm{~g}$ of fresh material in $1 \mathrm{ml}$ of $80 \%$ methanol followed up with a centrifugation at $7000 \times \mathrm{g}$ for $3 \mathrm{~min}$. The precipitate was washed and centrifuged twice in $0.5 \mathrm{ml}$ methanol. The supernatants were collected and subjected to a purification step. After washing by petroleum ether (three times), the aqueous phase was kept and then washed three times with ethyl acetate $(\mathrm{V} / \mathrm{V})$. The ethyl acetate extracts were collected and evaporated to dryness. Residues were then dissolved in Methanol (100\%) [29]. Concentrations of phenolics were estimated using the Folin Ciocalteu reagent. The optical density was determined at $760 \mathrm{~nm}$ and the level of phenolics was expressed as $\mu$ g equivalent of $(+)$-catechin per gram of fresh weight. The phenolic extracts were also separated and identified by HPLC with a Waters 600E liquid chromatograph (Waters Corporation, Paris, France) equipped with a Waters 990 photodiode array detector and Millipore software for data analysis. An efficient gradient of Acetonitrile-o-phosphoric acidified bidistilled water $(\mathrm{pH}$ 2.6) was used with an interchrom $\mathrm{Cl} 8$ reserved phase column (4.6 x $250 \mathrm{~mm}, 5 \mu \mathrm{m})$ (Waters Corporation). Twenty microlitres of each sample were analyzed at a flow rate of $1 \mathrm{ml} /$ min for $60 \mathrm{~min}$ according to a gradient.

\section{Cell Membrane Stability and Stomatal Resistance}

Three replicates of nine genotypes were grown in pots (six plants per pot) and irrigated normally were used to determine the cell membrane stability and stomatal resistance. After two months of growth, thirty leaf discs collected in triplicate from five fully expanded young leaves were used to evaluate the cell membrane stability. The discs were washed for $15 \mathrm{~min}$ in bidistilled water and exposed either to $0 \%$ (control) or to $30 \%$ PEG 6000 for $15 \mathrm{~h}$ in the dark. Electrolytes leakage was then measured before $(\mathrm{ECi})$ and after (ECf) 4 hours of rehydration and ultimately after autoclaving (ECt) the leaf discs (Bajji et al., 2004). The conductivity of measurements was made by an electrical conductivity meter (type HI 216). Cell membrane injuries were expressed as an index of injury (Id) calculated as:

$\mathrm{Id}=[(\mathrm{Rs}-\mathrm{Rc}) /(1-\mathrm{Rc})] \times 100$

Where Rs and Rc represent (Ecf-Eci/Ect-Eci) for control or PEG-treated tissues, respectively.

After sampling for electrolyte leakage, plants were stressed by withholding water for a period of 10 days. The stomatal resistance was measured on the upper (adaxial, $\mathrm{R}_{\mathrm{ad}}$ ) and lower (abaxial, $\mathrm{R}_{\mathrm{ab}}$ ) leaf surfaces on the second fully developed leaf from the top of the main culm $[30,31]$ using a DELTA-T, AP3 Porometer (Cambridge, UK). Total leaf resistance to water vapor $\left(\mathrm{R}_{\mathrm{L}}\left(\mathrm{s} / \mathrm{cm}^{2}\right)\right)$ was estimated assuming the two leaf surfaces acted as parallel resistors and was calculated as follows:

$\mathrm{RL}=(\operatorname{Rad} \times \operatorname{Rab}) /(\operatorname{Rad}+\mathrm{Rab})$

Six measurements were taken per each treatment per cultivar after 0 days (T0), 4 days (T4) and 10 days (T10) of withholding water.

\section{Growth Attributes}

Durum wheat plants were grown in a hydroponic system consisting of four boxes (four replicates) in which the seedlings were displaced randomly in black plastic trays. Boxes contains 18 litters of Adam's modified Hoagland's nutrient solution $(4 \mathrm{mM}$ $\mathrm{KNO}_{3} ; 4 \mathrm{mMCa}\left(\mathrm{NO}_{3}\right)_{2} ; 2 \mathrm{mM} \mathrm{MgSO}$. $7 \mathrm{H}_{2} \mathrm{O} ; 1 \mathrm{mM} \mathrm{KH} \mathrm{PO}_{4} 46$ $\mu \mathrm{M} \mathrm{H}_{3} \mathrm{BO}_{3} ; 50 \mu \mathrm{M}$ Fe-EDTA; $11 \mu \mathrm{M} \mathrm{MnCl} .4 \mathrm{H}_{2} \mathrm{O} ; 1.37 \mu \mathrm{M}$ $\mathrm{ZnSO}_{4} ; 0.5 \mu \mathrm{M} \mathrm{CuSO}_{4}$ and $\left.0.32 \mu \mathrm{M} \mathrm{MoO} 3\right)$. The $\mathrm{pH}$ of the solution was adjusted daily to $5.5+0.2$ using the concentrated $\mathrm{HCl}$ or $\mathrm{NaOH}$. Aeration of the nutrient solution was accomplished by an aquarium pump with attached perforated tubes at the bottom of each box. Maximum root length and 
shoot length were measured weekly under normal conditions. After four weeks, plants were harvested and tillers, leaves, and roots were counted. The shoots and roots were separated and dried in an oven at $80^{\circ} \mathrm{C}$ for 48 hours. The thickness of seminal root fragments of $2 \mathrm{~cm}$ length from the top was also checked under gradual microscopy.

\section{Statistical Analysis}

The data were subjected to the ANOVA one-way analysis of variance using SPSS 17 for Windows statistical software package. All values are expressed as means of three replicates except in hydroponic system where these values are means of four replicates. Correlations obtained were exploited to discuss the results.

\section{RESULTS}

\section{Phenolic Compounds Analysis}

Data analysis showed that accumulation of phenolics was stimulated under severe water deficit conditions (Figurel). Multiple comparisons (Tukey test, 5\%) revealed significant differences between the severely stressed mode of irrigation and each other modes. Under moderate stress conditions, no significant difference was obtained when compared to the control. The same results were obtained analyzing the normalized coefficients of the total phenolic content against the regime at $95 \%$. This test showed that only the severe stressed regime had a significant effect on total phenolic content. Comparing the genotypes, Karim and Ourghi showed the highest total phenolic content under severe stress and were estimated to 1374 and $1303 \mu \mathrm{g} \cdot \mathrm{g}^{-1} \mathrm{FW}$ for Karim and Ourghi respectively. Under the same conditions, genotypes Massa and Oum Rbia revealed the lowest amounts estimated respectively to 676 and $761 \mu \mathrm{g} \cdot \mathrm{g}^{-1} \mathrm{FW}$ (Figure 1).

In terms of phenolic accumulation under control and stressed conditions, two kinds of responses corresponding to two groups of genotypes were distinguished. The first group includes the genotypes Karim, Ourghi, Isly and Sebou with low amounts of phenolics before drought but an important accumulation under severely stressed conditions. For this group, the HPLC chromatograms of phenolic extracts revealed similar profiles between genotypes and under different stress situations. This group was characterized by an important accumulation of hydroxycinnamic acid derivatives and compounds belonging to the flavonoids family (Figure 2) under drought stress conditions. The second group includes the genotypes Sarif, Marzak, Vitron, Oum Rbia and Massa for which significant differences between control and drought conditions were revealed. HPLC chromatograms revealed the presence of flavonoids and negligible amounts (absent in some genotypes) of hydroxycinnamic acid derivatives (Figure 2). Except for genotype Sarif, where drought stress has no effect on phenolic accumulation, application of stress-induced large variation in flavonoid contents and in some genotypes (Massa for example) small accumulation of hydroxycinnamic acid derivatives.

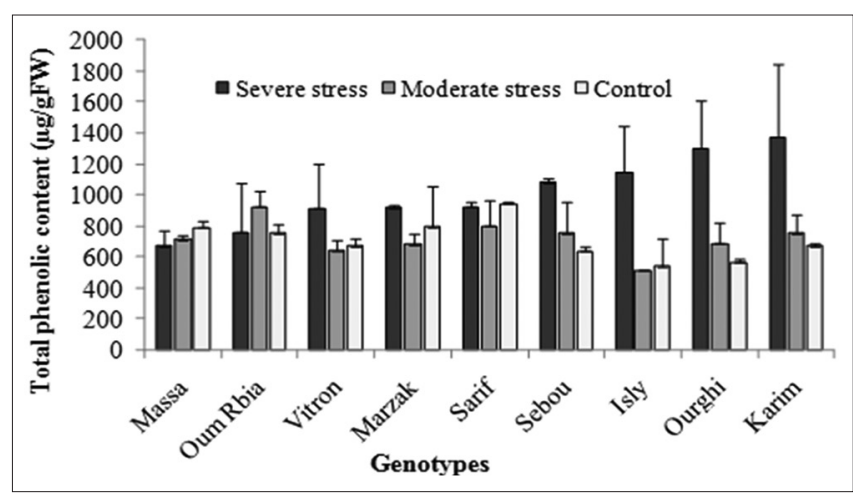

Figure 1: Effect of drought on soluble phenolic contents of 9 durum wheat genotypes grown in pots

In addition, comparison of HPLC chromatograms (Figure 2) revealed a large difference between genotypes. Variations were revealed as a function of the genotype and the stress degree. This study reveals the presence of different compounds representing different phenolic families (flavans, hydroxycinnamic acid derivatives, and flavonoïds). When compared, the less accumulating (Oum Rbia) and the more accumulating (Karim) cultivars revealed different ways in response to phenolic accumulation. The comparison shows that water stress response of Karim is manifested by an accumulation of hydroxycinnamic acid derivatives such as a ferulic acid (peak2) and by an accumulation of a flavonoïd compound (peak5) in the less accumulating genotype Oum Rbia.

\section{Peroxidases Activity}

The effect of drought on POX activity was studied in parallel to phenolic content evaluation. Compared to control and moderate stress, the highest POX activity was obtained under severe stress conditions. Genotypes Isly, Ourghi, and Sebou showed the highest POX activity estimated to $278 \mathrm{U} / \mathrm{g} \mathrm{FW}$, $251 \mathrm{U} / \mathrm{g} \mathrm{FW}$, and $247 \mathrm{U} / \mathrm{g} \mathrm{FW}$ respectively. The lowest POX activity was registered for genotypes Oum Rbia under both severe and moderate stress and was $158 \mathrm{U} / \mathrm{g} \mathrm{FW}$ and $89 \mathrm{U} / \mathrm{g}$ FW respectively (Figure 3).

Comparing the varieties, the most significant differences were obtained under control and moderate stress. However, in spite of the highest activity observed under severe stress, this mode of irrigation is not convenient to use for genotypes discrimination. The varieties Karim and Massa revealed a maximum POX activity under control conditions. As drought stress increase, POX activity increases significantly in varieties Sebou, Isly, and Ourghi comparing to others varieties. The effect of wheat variety on POX was not significant under severe stress (Figure 3).

\section{Cell Membrane Stability and Stomatal Resistance}

Evaluation of cell damage degree was accomplished for the nine genotypes using the electrolyte leakage measurements. This parameter, indicated here (Figure 4) by cell damage index (Id) revealed an important genotypic variability between genotypes (ANOVA one-way, 0.05 ) in response to in vitro stress induced 


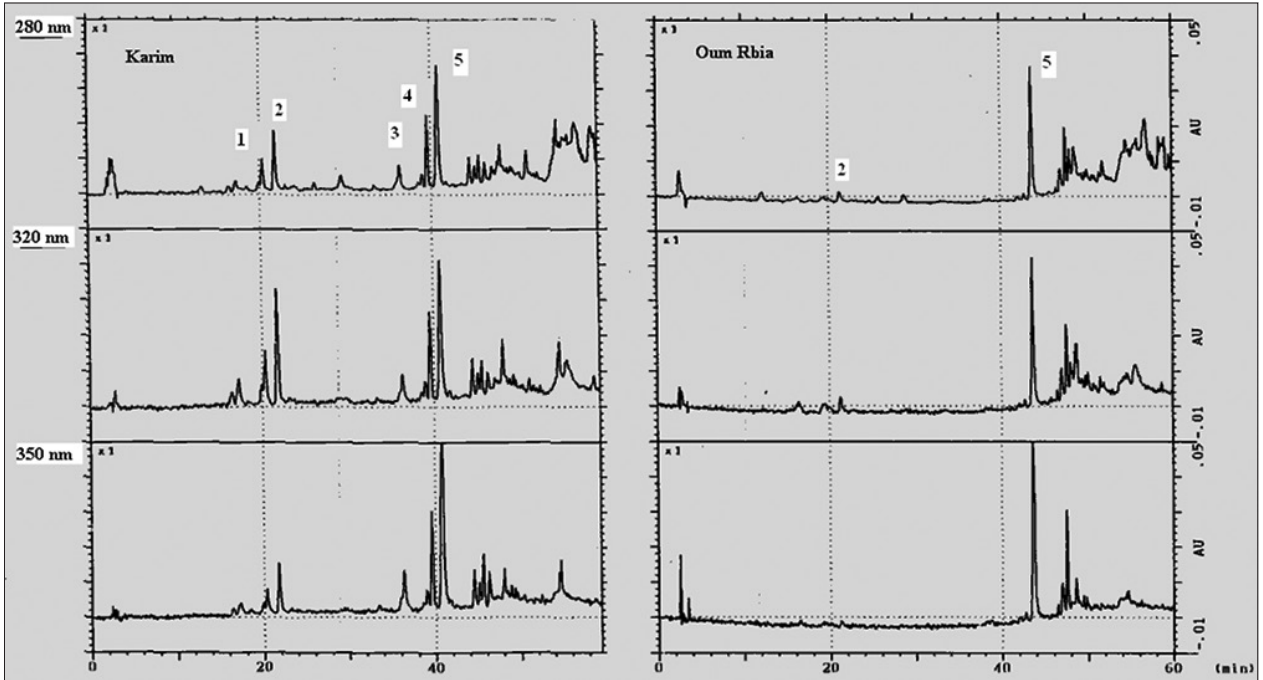

Figure 2: HPLC chromatograms of phenolics extracts of two durum wheat genotypes Karim and Oum Rbia grown in pots under severely stressed conditions

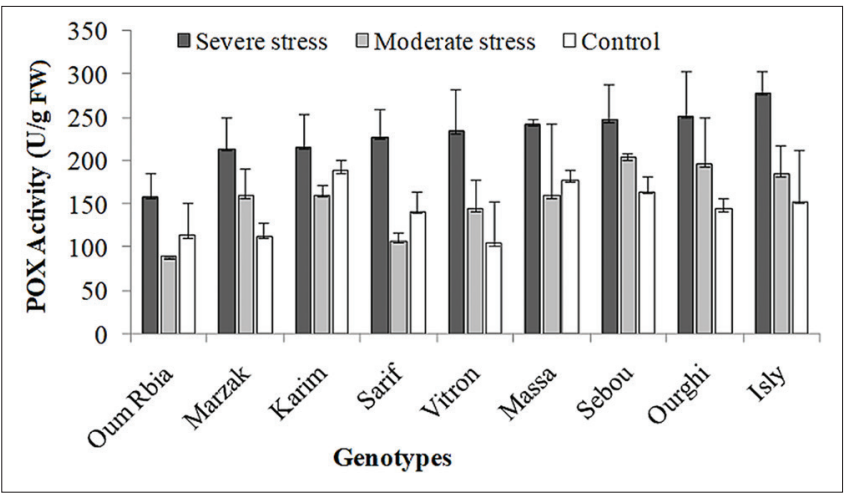

Figure 3: Effect of drought stress on peroxidase activity of 9 durum wheat genotypes grown in pots.

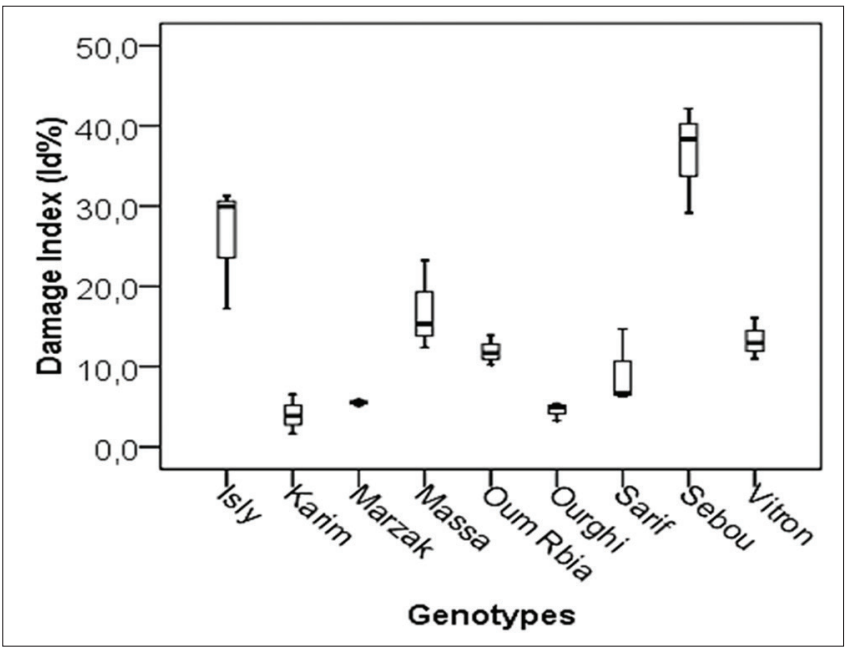

Figure 4: Variation of cell membrane stability (damage index) of nine durum wheat genotypes grown in pots after exposure to PEG $30 \%$.

by PEG. The highest percentages of damaged cells obtained were estimated to $36 \%$ and $26 \%$ for genotypes Sebou and Isly respectively. In contrast, genotypes Karim, Ourghi, and Marzak revealed the lowest damage index estimated to $4 \%, 4.5 \%$, and $5.5 \%$ respectively. The remaining genotypes showed an intermediate damage degree ranging from $9 \%$ to $17 \%$ and include the genotypes Sarif, Oum Rbia, Vitron, and Massa. As ions leakage is generally linked to osmotic adjustment, differences obtained should explain the osmotic adjustment potential differences between genotypes and may help to discriminate between genotypes showing similar responses with regard to other physiological and/or biochemical parameters. Regarding the stomatal resistance, this parameter increases progressively with increasing the period of withholding water. After cessation of watering for 10 days, stomatal resistance revealed significant differences between genotypes and allowed to distinguish between drought tolerant (Marzak, Karim, Isly, Massa, and Ourghi) and drought sensitive (Sarif, Vitron, Sebou and Oum Rbia) genotypes (Figure 5).

\section{Growth Attributes}

During 28 days of growing in a hydroponic system, measurements on root and shoot growth were taken weekly. After this period, plants were harvested; leaves and roots were counted, dried and weighed. The dry matter accumulation and allocation to the roots was estimated by the root/shoot ratio and was compared for all the genotypes. Multiple comparisons and ANOVA analysis revealed no significant differences in term of maximum root length, except for Marzak which shows a significant difference with Isly and Sebou genotypes after two weeks of growth. However, significant differences between genotypes were obtained in term of shoot length. During the first three weeks, genotypes Sebou and Karim showed tall shoots while Oum Rbia and Isly revealed short shoots. In term of root/shoot length ratio, major differences were obtained mainly after 2 and 3 weeks of growth. The best ratios were obtained for Isly and Oum Rbia after two and three weeks respectively. Except for Karim and Sarif, where the maximum R/S length ratio was obtained after four weeks, all genotypes revealed a maximum R/S length ratio after three weeks of growth (Figure 6). 
At harvest, the genotype Karim showed the highest tillers number ( 3.75 per plant) and leaves number ( 14.75 per plant) and relatively high root number ( 15.25 per plant). This genotype exhibited also the maximum root dry weight (191.75 mg per plant) and maximum root thickness $(0.61 \mathrm{~mm})$ (Table 1$)$. In contrast, genotype Sebou exhibited a minimum root dry weight (128.25 mg per plant), low root number and maximum shoot dry weight (minimum root/shoot dry weight ratio). In addition, root thickness may contribute to differences between genotypes in term of total root biomass.

\section{DISCUSSION}

Under drought stress conditions, there will be changes in plants morphology, physiology and biochemical reactions. They are

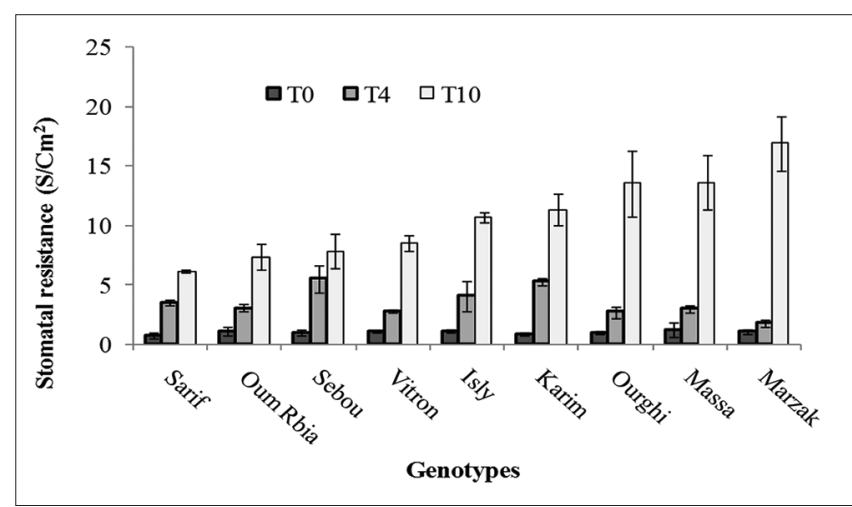

Figure 5: Variation of leaf stomatal resistance of 9 durum wheat genotypes growing in pots after 0,4 and 10 days of withholding water.

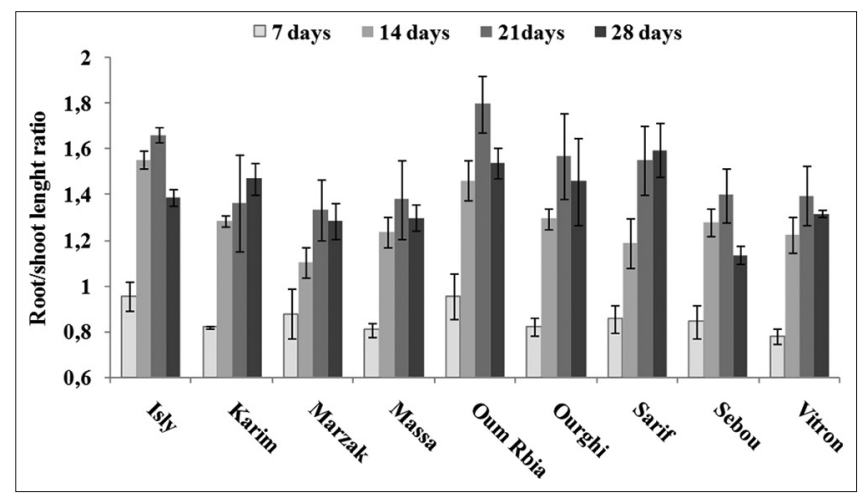

Figure 6: Variation of root/shoot length ratio of 9 durum wheat genotypes grown in hydroponic system. affected by those constraints at the anatomical levels [32]. In the present study, we revealed an important stimulation of phenolics accumulation and POX activity in response to drought. Similar results were recently obtained [7] and showed a noticeable increase in levels of antioxidative enzymes, reactive oxygen species production, $\mathrm{R} / \mathrm{S}$ ratio and chlorophyll content. Under severe water deficit, the genotypes Karim and Ourghi showed the highest amounts of total phenolic contents, while Massa and Oum Rbia showed the lowest amounts and the remaining genotypes revealed intermediate amounts. Ourghi was also characterized by high POX activity while Karim and Massa revealed an average enzymatic activity and Oum Rbia showed the lowest activity. In fact, the accumulation of phenolics and increase in POX activity were considered in previous studies as indicators of plant resistance against diseases $[33,34]$ and drought stress $[35,10]$. Accumulation of phenolics in response to abiotic stresses is well known as a protection strategy in plants $[36,37,38]$. Under water-stress, a decrease in plant biomass of Hypericum brasiliense with increasing the phenolic contents has been reported [37]. Under stressful environments, plants produced more reactive oxygen species which activates the synthesis of antioxidants such as phenolics or other radical scavenging systems to prevent cell death [16]. The authors found a positive correlation between scavenging activities and phenolics accumulation particularly the hydroxycinnamic acid derivatives. Similar ascertainment was obtained [10] and revealed that phenolic content and antioxidant enzymes increases in response to drought stress or drought and salinity combined stress. The POX is implicated in many detoxifying systems and plays an important role in preventing irreversible damage to photosynthetic machinery. Antioxidative enzymes such as POX may be used as a strategy to minimize oxidative damage and to maintain the physiological plant stability [39].

The genotypes Karim and Ourghi (with higher phenolic contents) showed also the highest cell membrane stability (low damage index) as compared to Massa and Oum Rbia. In fact, ROS can results in peroxidation of membanes, organelles and enzyme activation or inactivation. Maintenance of membrane integrity and function is a long-standing method to fight against stresses like drought [14]. This method based on measuring solute leakage from plant tissue has been used to compare the osmotic adjustment of wheat and maize under drought stress conditions [40]. The membrane stability was tested in melon (Cucumis melo L.) under salt stress conditions, this parameter decreases by $30 \%$ in presence of $90 \mathrm{mM} \mathrm{NaCl}$ and was linked to peroxidase

Table 1: Root and shoot growth parameters of the nine studied durum wheat genotypes grown for 28 days in hydroponic. No: Number; DW: Dry Weight; Thick: thickness

\begin{tabular}{|c|c|c|c|c|c|c|}
\hline Genotypes & Tillers No & Leaves No & Root No & Root DW (mg) & Shoot DW (mg) & Root Thickness (mm) \\
\hline Sebou & $2.75 \pm 0.25$ & $10 \pm 0.41$ & $13.75 \pm 1.31$ & $128.25 \pm 13.2$ & $623 \pm 40.6$ & $0.6 \pm 0.03$ \\
\hline Isly & $2.25 \pm 0.25$ & $9.5 \pm 0.5$ & $10.75 \pm 0.48$ & $158.75 \pm 46$ & $502 \pm 107$ & $0.53 \pm 0.1$ \\
\hline Vitron & $3.25 \pm 0.25$ & $11.5 \pm 0.5$ & $15 \pm 0.71$ & $142.7 \pm 31$ & $433 \pm 78$ & $0.53 \pm 0.08$ \\
\hline Karim & $3.75 \pm 0.25$ & $14.75 \pm 0.85$ & $15.25 \pm 0.85$ & $191.75 \pm 8.28$ & $470.5 \pm 59.4$ & $0.61 \pm 0.07$ \\
\hline Marzak & $2.75 \pm 0.25$ & $10.25 \pm 0.48$ & $14.75 \pm 0.25$ & $129.5 \pm 6.3$ & $506 \pm 51.46$ & $0.52 \pm 0.06$ \\
\hline Oum Rbia & $2.75 \pm 0.48$ & $10 \pm 0.71$ & $14.5 \pm 0.65$ & $113.75 \pm 19.3$ & $453.5 \pm 51$ & $0.5 \pm 0.05$ \\
\hline Massa & $3 \pm 0.00$ & $10.75 \pm 0.75$ & $15.25 \pm 1.31$ & $144.5 \pm 4.7$ & $513 \pm 96$ & $0.53 \pm 0.03$ \\
\hline Ourghi & $2.5 \pm 0.29$ & $9.25 \pm 0.25$ & $15.5 \pm 1.32$ & $140 \pm 9.3$ & $483.7 \pm 66.5$ & $0.46 \pm 0.03$ \\
\hline Sarif & $3 \pm 0.00$ & $11.5 \pm 0.29$ & $13.25 \pm 0.75$ & $159.75 \pm 10.5$ & $380.75 \pm 67.6$ & $0.55 \pm 0.07$ \\
\hline
\end{tabular}


activity which increases 3.6 under the same conditions [12]. In wheat, this technique was used as a physiological index for the evaluation of drought tolerance degree $[11,15,14]$ or to compare it with other crop species like barley and sorghum [41]. In the present work, a positive correlation was revealed between high cell membrane stability (low damage index) and high phenolic contents and POX activity under drought conditions. Similar results were obtained when evaluating the peroxidases activity and membrane stability of wheat plants under drought stress conditions [35]. The authors showed that tolerant genotypes had highest peroxidase activity and high cell membrane stability, while susceptible genotypes were characterized by the low activity of antioxidant enzymes and low membrane stability [42]. Stomatal resistance is also an important physiological mechanism implicated in wheat response to environmental stress factors like drought. Here, the genotypes showing high POX activity, high phenolic contents and low damage index revealed a high degree of stomatal closure. According to some studies, the high stomatal resistance is generally characterized by high water use efficiency and is often found to maintain lower leaf internal $\mathrm{CO} 2$ concentration $(\mathrm{Ci})$ [43].

As a conclusion to this investigation, the importance of phenolic compounds and peroxidase activity in drought tolerance has been highlighted. In fact, the phenolic content and the POX activity increase as a consequence of the water-stress conditions improvement and reveal the importance of these indicators in Durum wheat plant drought tolerance.

At the cellular level, the electrolyte leakage obtained under the stress conditions in vitro using PEG can provide pieces of information on the degree of cell membrane damages which is associated to the degree of osmotic adjustment and thus to the water stress tolerance. At the morphological level, hydroponic screen identified significant variation between genotypes in term root thickness; tillers; leaves and roots number per plant. These parameters indicate the adaptability of the genotypes to water-scarce environments.

The integration of all these parameters could help in the selection of drought tolerant genotypes. The POX activity, phenolic content, membrane stability, stomatal resistance, R/S ratio may be good parameters for selecting drought tolerant genotypes of durum wheat. However, further studies are needed to confirm the performance of root system traits in order to support water deficit under field and greenhouse conditions. The root lignification degree, their response to the physical resistance of the soil and their ability to explore deep soil layers are some aspects to be developed.

\section{ACKNOWLEDGMENTS}

Financial support for this work was provided by the project INCO-CEDROME N ${ }^{\circ} 015468$ and the CNRST Rabat, Morocco.

\section{REFERENCES}

1. Chandrasekar V, Sairam RK, Srivastava GC. Physiological and Biochemical Responses of Hexaploid and Tetraploid Wheat to
Drought Stress. Journal of Agronomy and Crop Science. 2000; 185:219-227

2. Gupta NK, Sunita G, Arvind K. Effect of Water Stress on Physiological Attributes and their Relationship with Growth and Yield of Wheat Cultivars at Different Stages. Journal of Agronomy and Crop Science. 2001; 186, 55-62.

3. Rampino P, Pataleo S, Gerardi C, Mita G, Perrotta C. Drought stress response in wheat: physiological and molecular analysis of resistant and sensitive genotypes. Plant Cell and Environment. 2006; 29:21432152.

4. Sgherri C, Milone MTA, Clijsters H, Navari-Izzo F. Antioxidative enzymes in two wheat cultivars, differently sensitive to Drought and Subjected to subsymptomatic copper doses. Journal of Plant Physiology. 2001: 158:1439-1447.

5. Nayyar H, Gupta D. Differential sensitivity of C3 and C4 plants to water deficit stress: Association with oxidative stress and antioxidants. Environmental and Experimental Botany. 2006; 58:106-113.

6. Nemat Allah MM, Hassan NM. Changes of antioxidants levels in two maize lines following atrazine treatments. Plant Physiology and Biochemistry. 2006; 44:202-210.

7. Zhang C, Shi S, Wang B, Zhao J. Physiological and biochemical changes in different drought tolerant alfalfa (Medicago sativa L.) varieties under PEG-induced drought stress. Acta Physiologiae Plantarum. 2018; 40: 1-19.

8. Huseynova I M, Aliyeva D R, Aliyev J A. Subcellular localization and responses of superoxide dismutase isoforms in local wheat varieties subjected to continuous soil drought. Plant Physiology and Biochemistry. 2014; 81:54-60.

9. Tatari M, Ghazvini R F, Mousavi A, Babaei G. Comparison of Some Physiological aspects of Drought Stress Resistance in Two Ground Cover Genus, Journal of Plant Nutrition. 2017. DOI: 10.1080/01904167.2017.1346117

10. Ahmed IM, Nadira UA, Bibi N, Cao F, He X, Zhang G, Feibo W. Secondary metabolism, and antioxidants are involved in the tolerance to drought and salinity, separately and combined, in Tibetan wild barley. Environmental and Experimental Botany. 2014; 111:1-12.

11. Farooq S, Farooqe A. The use of cell membrane stability (CMS) technique to screen for salt tolerant wheat varieties. Journal of Plant Physiology. 2006; 163:629-637.

12. Sarabi B, Bolandnazar S, Ghaderi N, Ghashghaie J. Genotypic differences in physiological and biochemical responses to salinity stress in melon (Cucumis melo L.) plants: Prospects for selection of salt tolerant landraces. Plant Physiology and Biochemistry. 2017. doi: 10.1016/j.plaphy.2017.09.006.

13. Prasil I, Zamecnek J. The use of a conductivity measurement method for assessing freezing injury I. Influence of leakage time, segment number, size and shape in a sample on evaluation of the degree of injury. Environmental and Experimental Botany. 1998; 40:1-10.

14. Bajji M, Kinet JM, Lutts S. The use of the electrolyte leakage method for assessing cell membrane stability as a water stress tolerance test in durum wheat, Plant Growth Regulation. 2001; 00:1-10.

15. Dhanda SS, Sethi GS, Behl RK. Indices of Drought Tolerance in Wheat Genotypes at Early Stages of Plant Growth. Journal of Agronomy and Crop Science. 2004; 190:6-12.

16. Meot-Duros L, Mangé $C$. Antioxidant activity and phenol content of Crithmum maritimum L. leaves. Plant Physiology and Biochemistry. 2009; 47:37-41.

17. Torrecillas A, Alarcon JJ, Domingo R, Planesa J, Sknchez-Blancoa MJ. Strategies for drought resistance in leaves of two almond cultivars. Plant Science. 1996; 118, 135-143.

18. Subrahmanyam D, Subash N, Haris A, Sikka AK. Influence of water stress on leaf photosynthetic characteristics in wheat cultivars differing in their susceptibility to drought. Photosynthetica. 2006; 44:125-129.

19. Pou A, Flexasa J, Mar Alsinab M, Bota J, Carambulaa C, Herraldeb F, Galme'sa J, Lovisoloc C, Jime'nezd M, Ribas-Carbo'M, Rusjane D, Secchic F, Toma 'sa M, Zso' fif Z, Medrano H. Adjustments of water use efficiency by stomatal regulation during drought and recovery in the drought-adapted Vitis hybrid Richter-110 (V. berlandieri V. rupestris). Physiologia Plantarum, 2008; 134:313-323.

20. Leilah AA, Al-Khateeb SA. Statistical analysis of wheat yield under drought conditions, Journal of Arid Environments, 2005; 61:483-496.

21. Zhang $X Y$, Chen SY, Sun HY, Pei D, Wang YM. Dry matter, harvest index, grain yield and water use efficiency as affected by water supply 
in winter wheat, Irrigation Science. 2008, 27:1-10.

22. Rivelli AR, James RA, Munns R, Condon AGT. Effect of Salinity on Water relations and Growth of Wheat Genotypes with Contrasting Sodium Uptake. Functional Plant Biology. 2002; 29:1065-1074.

23. Barbour NW, Murphy CF. Field Evaluation of Seedling Root Length Selection in Oats. Crop Science, 1983; 24:165-169.

24. Outoukarte I, Belaqziz M, Price A, Nsarellah N, El Hadrami I. Durum Wheat Root Distribution and Agronomical Performance as Influenced by Soil Properties. Crop Science. 2010; 50:803-807.

25. Menge DM, Kameoka E, Kano-Nakata M, Yamauchi A. Asanuma S, Asai H, Kikuta M, Suralta RR, Koyama T, Tran TT, Siopongco JDLC, Mitsuya S, Inukai Y, Makihara D. Drought-induced root plasticity of two upland NERICA varieties under conditions with contrasting soil depth characteristics. Plant Production Science. 2016; 1-12.

26. Matsui T, Singh BB. Root Characteristics in Cowpea Related to Drought Tolerance at the Seedling Stage. Experimental Agriculture, 2003; 39:29-38.

27. Equiza M, Miravé JP, Tognetti JA. Differential Inhibition of Shoot vs. Root Growth at Low Temperature and its Relationship with Carbohydrates Accumulation in Different Wheat Cultivars. Annals of Botany. 2001; 80:657-663.

28. Baaziz M, Saaidi M. Preliminary identification of date palm cultivars by esterase isoenzymes and peroxidase activities. Canadian Journal of Botany. 1988; 66: 89-93.

29. El Hadrami I, Ramos T, El Bellaj M, El Idrissi Tourane A, Macheix JJ. A sinapic derivative as induced defense compound of date palm against Fusarium oxysporum f. sp. abledinis, the agent causing bayoud disease. Journal of Phytopathology. 1997; 145:329-333.

30. Beardsell MF, Cohen D. Relationships between Leaf Water Status, Abscisic Acid Levels, and Stomatal Resistance in Maize and Sorghum. Plant Physiology. 1975; 56:207-212.

31. O'Toole JC, Cruiz RT. Response of Leaf Water Potential, Stomatal Resistance, and Leaf Rolling to Water Stress, Plant Physiology. 1980; 65:428-432.

32. Beck HE, Fettig S, Knake C, Hartig K, Bhattarai T. Specific and unspecific responses of plants to cold and drought stress. Journal of Biosciences. 2007; 32:501-510
33. Tyagi M, Kayastha AM, Sinha B, The Role of Phenolics and Peroxidase in Resistance to Alternaria tritidna in Bread Wheat (Triticum aestivum L.). Journal of Agronomy and Crop Science. 1998; 181:29-34.

34. Menden B, Kohlhoff M, Moerschbacher BM. Wheat cells accumulate a syringyl-rich lignin during the hypersensitive resistance response. Phytochemistry. 2007; 68:513-520.

35. Sairam RK, Saxena DC. Oxidative Stress and Antioxidants in Wheat Genotypes: Possible Mechanism of Water Stress Tolerance. Journal of Agronomy and Crop Science. 2000; 184:55-61.

36. Kuk YI, Shin JS, Burgos NR, Hwang TE, Han O, Ho Cho B, Jung S, Guh JO. Antioxidative Enzymes Offer Protection from Chilling Damage in Rice Plants. Crop Science. 2003; 43, 2109-2117.

37. Nacif Al, Mazzafera P. Effect of water and temperature stress on the content of active constituents of Hypericum brasiliense Choisy. Plant Physiology and Biochemistry. 2005; 43:241-248.

38. Cheruiyot EK, Mumera LM, NG'Etich WK, Hassanali A. Wachira F, Polyphenols as Drought Indicators for Drought Tolerance in Tea (Camellia sinensis L.). Biosciences Biotechnology and Biochemistry. 2007; 71: 2190-2197.

39 Jiang $M$, Zhang J. Water stress-induced abscisic acid accumulation triggers the increased generation of reactive oxygen species and up-regulates the activities of antioxidant enzymes in maize leaves. Journal of Experimental Botany. 2002; 53:2401-2410.

40 Nayyar H. Accumulation of osmolytes and osmotic adjustment in water-stressed wheat (Triticum aestivum) and maize (Zea mays) as affected by calcium and its antagonists. Environmental and Experimental Botany. 2003; 50:253-264.

41 Blum A, Ebercon A. Cell Membrane Stability as a Measure of Drought and Heat Tolerance in Wheat. Crop Science. 1981; 21:43-47.

42 Reynolds MP, Nagarajan S, Razzaque MA, Ageeb OAA. Heat tolerance: Application of Physiology in Wheat Breeding. In: Reynolds M.P., OrtizMonastereo J.I., McNab A., Eds. Application of Physiology in Wheat Breeding Mexico, DF CIMMYT: 124-135. 2001

43 Earl HJ. Stomatal and non-stomatal restrictions to carbon assimilation in soybean (Glycine max) lines differing in water use efficiency. Environmental and Experimental Botany. 2002; 48:237-246. 